\title{
Influence of Binary Oxidant (FeCl 3 :APS) Ratio on the Spectroscopic and Microscopic Properties of Poly(2,5-Dimethoxyaniline)
}

\author{
Rajiv K. Singh ${ }^{1 *}$, Amit Kumar ${ }^{1}$, Khushboo Agarwal ${ }^{1}$, Deepshikha Dwivedi ${ }^{2}$, Keadar N. Sood ${ }^{1}$, \\ Ramadhar Singh ${ }^{1}$ \\ ${ }^{1}$ National Physical Laboratory, Council of Scientific \& Industrial Research, New Delhi, India \\ ${ }^{2}$ Department of Physics, Kanya Gurukul Mahavidyalaya, Gurukul Kangri University, Haridwar, India \\ Email: *rajivsingh@mail.nplindia.ernet.in
}

Received June 10, 2012; revised July 16, 2012; accepted July 27, 2012

\begin{abstract}
Poly(2,5-dimethoxyaniline) (PDMA) has been synthesized by chemical oxidative polymerization technique using varying ratio (wt/wt) of binary oxidants; ferric chloride $\left(\mathrm{FeCl}_{3}\right)$ and ammonium persulfate (APS). Fourier transform infrared (FT-IR) and ultraviolet-visible (Uv-vis) spectroscopic investigations provide the evidence of the presence of both benzenoid and quinoid ring units. The thermal analysis and structural characterization data suggests that the oxidant ratio greatly controls the molecular ordering in PDMA. Surface morphology shows the existence of both amorphous and crystalline domains wherein the crystalline domain size depends on the oxidant ratio. The de conductivity $\left(\sigma_{\mathrm{dc}}\right)$ of PDMA is also a function of binary oxidant ratio and at $\mathrm{FeCl}_{3}$ :APS (50:50), it increases by two orders of magnitude. Films of PDMA synthesized using $\mathrm{FeCl}_{3}$ :APS (50:50) binary oxidant exhibits a decrease in the surface current on exposure to ammonia gas.
\end{abstract}

Keywords: Poly(2,5-Dimethoxyaniline); Binary Oxidant; Structured Polymer; DC Conductivity

\section{Introduction}

Conducting polymers, because of their application in a variety of technologically important devices such as sensors, organic field effect transistors, rechargeable batteries, organic photovoltaics and energy storage systems, have been of great research interest for the last two decades [1-6]. This is a natural consequence of their remarkable chemical and physical attributes. The fact that the opto-electronic and magnetic properties of conducting polymers are dependent on the synthesis and processing conditions and offers unique opportunity of tailoring the former by manipulating the later. The one dimensional nano-structured conducting polymers are also of interest to researchers because of its applications in molecular, electronic and electrochromic display devices [7]. It has been shown [8-10] that the electronic transport of conducting polymers bears a strong correlation with its structural and morphological factors. Among the family of conducting polymers, polyaniline (PANI) is one of the most widely investigated materials [11]. The key factors that have driven extensive research on PANI are its high conductivity, environmental stability and low cost of

${ }^{*}$ Corresponding author. synthesis. The major applications of PANI have been in the area of anti-corrosion coatings, sensors and electrochromic devices $[5,7,12]$. In spite of its wide applicability, the limiting factor of PANI is its poor processability in common organic solvents as well as its thermal degradation during melts processing.

Poly(2,5-dimethoxyaniline) (PDMA) is a derivative of PANI and has same conjugated backbone. It exists in three distinctive forms with varying ratio of benzenoid and quinoid ring units present such as: 1) leucoemeraldine; 2) pernigraniline and 3) emeraldine forms (Figure 1). The extent of presence of one or more forms depends upon the synthesis conditions and the post synthesis treatments. The electrical conductivity of PANI is mainly governed by the presence of these forms. In order to improve its processability, complexation of polyaniline with sulphonic acid has been attempted earlier [13]. Another path to make the PANI solution processable is the use of substituted polyanilines i.e. making derivatives of polyanilines $[14,15]$. In case of processable substituted PANI, it has been observed that the di-substituted PANI exhibits higher conductivity as compared to its monosubstituted form. PDMA has higher conductivity than poly(2-methoxyaniline) [16]. Nano-particles synthesized 
by PANI are also widely reported in literature as they are processable by dispersion in common organic solvents [11]. One dimensional nano-structures of PANI is being synthesized by chemical oxidative or electrochemical polymerization of monomer with the help of surfactant acting as a template, [17] whereas PANI nanorods and nanotubes have been synthesized without using any surfactant $[8,18]$. Formation of a cluster of hexagonal nanorods of PANI is also reported in literature [10] by using binary oxidants during its synthesis. The advantages of nano-structured polymers are its better carrier transport and electrochemical activity. Recently, the room temperature dc conductivity $\left(\sigma_{\mathrm{dc}}\right)$ and the charge transport in PDMA has been reported and explained by using Mott's three dimensional variable range hopping (3D-VRH) conduction mechanism [19].

We report here the influence of binary oxidants such as ferric chloride $\left(\mathrm{FeCl}_{3}\right)$ and ammonium persulfate (APS) ratio on the spectroscopic, microscopic and electrical properties of chemically synthesized PDMA. The structure-conductivity correlation is evidenced by the change in the ratio of binary oxidant, which controls the crystallinity as well as its electrical conductivity. The possibility of using PDMA as ammonia gas sensing device is also explored.

\section{Experimental}

Different samples of PDMA have been synthesized by using chemical oxidative polymerization technique in acidic medium $(\mathrm{pH} \sim 2)$ at $278 \mathrm{~K}$ in an inert atmosphere by varying the ratio of oxidants (wt/wt ratio) i.e. ferric chloride $\left(\mathrm{FeCl}_{3}\right)$ and ammonium persulfate (APS). The details of synthesis procedure and purification process to get pristine PDMA have been reported in our recent work [19]. Five samples of PDMA were synthesized and designated as PDMA1, PDMA2, PDMA3, PDMA4 and PDMA5 as per the ratio of binary oxidants (Table 1). The percentage yield of PDMA3 having $\mathrm{FeCl}_{3}$ :APS (50:50 $\mathrm{wt} \%$ ) is higher than other four samples of PDMA.

Fourier transform infrared (FT-IR) measurements were carried out on the powder form of the samples; PDMA1, PDMA2, PDMA3, PDMA4 and PDMA5 using Nicolet FT-IR spectrometer in the range $4000-400 \mathrm{~cm}^{-1}$. Ultraviolet-visible (Uv-vis) spectrograms of the above mentioned samples were obtained using Perkin-Elmer Cambda 25 spectrometer in the range $200-1100 \mathrm{~nm}$. Solution of PDMA was casted by solution evaporation technique at room temperature on quartz substrate for Uv-vis characterization. Scanning electron microscopy (SEM) was performed by Leo 440 and Ziess EVO MA-10 scanning electron microscope in order to examine the structural morphology of the synthesized polymer. X-ray diffraction patterns were taken by Rigaku-make Powder X-ray diffracttometer by using $\mathrm{Cu}-\mathrm{K} \alpha(\lambda=1.5404 \AA)$ radiation. The room temperature dc conductivity $\left(\sigma_{\mathrm{dc}}\right)$ measurement, on rectangular pellets of all the samples in a metal-polymermetal $(m-p-m)$ structure, has been performed by using Keithley 6517A Electrometer. The $\sigma_{\mathrm{dc}}$ of all the samples [19] along with their percentage yield are reported in Table 1.

Aqueous solution of partially soluble sample PDMA3 was spin casted on indium-tin-oxide (ITO) coated glass substrate. The pressure contacts were made through copper clips on ITO substrate and change in the surface current of the casted film on exposure to different volume of ammonia gas (purity 99.99\%) was measured using Keithley 4200 Semiconductor Characterization System. A cylindrical teflon cell (dia. $\times$ height $\sim 4 \times 8 \mathrm{~cm}^{2}$ ) was designed for ammonia sensing applications in which the sample was hanged and connections were taken through O-ring. The cell was evacuated using oil free rotary pump and sample was flushed by pure nitrogen gas before each sensing measurement. The changes in surface current was measured through $\mathrm{I}-\mathrm{V}$ investigation with respect to blank run done in absence of ammonia gas to that of the surface current after insertion of measured volume of ammonia gas $(2,5,7$ and $10 \mathrm{cc})$ into the Teflon cell.

\section{Results and Discussion}

Figure 1 shows probable chemical structure of three

Table 1. Percentage yield of the polymer obtained using different oxidants ratio and their room temperature ( 300 K) dc conductivity $\left(\sigma_{\mathrm{dc}}\right)$ of various samples of PDMA.

\begin{tabular}{ccccc}
\hline Samples & $\begin{array}{c}\mathrm{FeCl}_{3} \\
(\mathrm{wt} \%)\end{array}$ & $\begin{array}{c}\text { APS } \\
(\mathrm{wt} \%)\end{array}$ & $\begin{array}{c}\text { Percentage } \\
\text { Yield }(\%)\end{array}$ & $\begin{array}{c}\mathrm{dc} \text { Conductivity } \sigma_{\mathrm{dc}} \\
\left(\mathrm{S} \cdot \mathrm{cm}^{-1}\right)(\sim 300 \mathrm{~K})\end{array}$ \\
\hline PDMA1 & 100 & 0 & 45 & $5.84 \times 10^{-8}$ \\
PDMA2 & 75 & 25 & 50 & $2.74 \times 10^{-7}$ \\
PDMA3 & 50 & 50 & 63 & $9.44 \times 10^{-7}$ \\
PDMA4 & 25 & 75 & 47 & $6.32 \times 10^{-8}$ \\
PDMA5 & 0 & 100 & 24 & $7.72 \times 10^{-9}$ \\
\hline
\end{tabular}

(a)

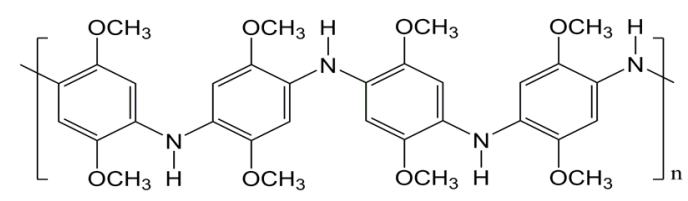

(b)

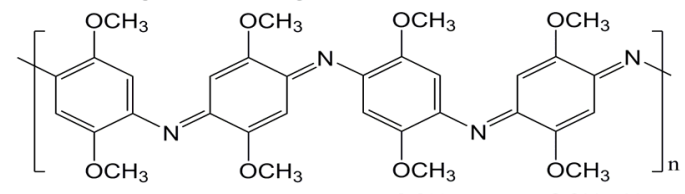

(c)

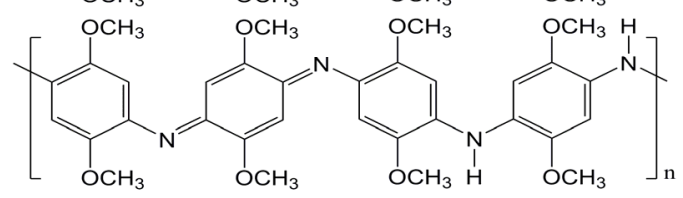

Figure 1. Chemical structure of three different forms of poly(2,5-dimethoxyaniline). (a) Leucoemeraldine; (b) Pernigraniline; and (c) Emeraldine form. 
oxidative states of PDMA (with varying ratio of benzenoid and quinoid ring units present such as (a) leucoemeraldine, (b) pernigraniline and (c) emeraldine.

The experimental observations of the present work have been explained in terms benzenoid and quinoid ring units whose ratio governs the overall behavior of the synthesized polymer. FT-IR and Uv-vis. spectroscopic investigations confirm the existence of combinations of benzenoid and quinoid forms in PDMA synthesized for the present investigation.

\subsection{FT-IR Analysis}

FT-IR spectra of PDMA1, PDMA2, PDMA3, PDMA4 and PDMA5 are shown in Figure 2.

The significant band assignments of the characteristic absorption peaks are listed in Table 2 .

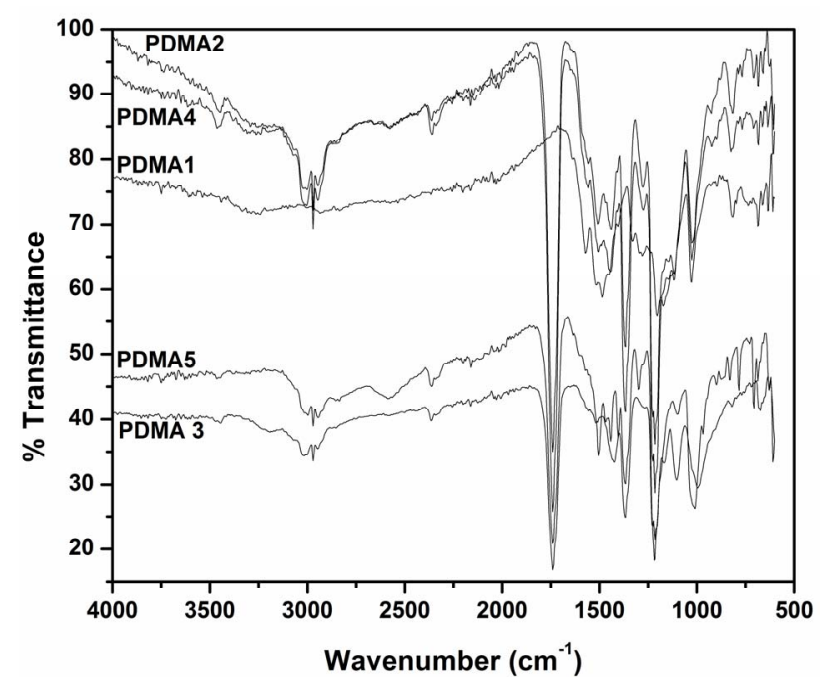

Figure 2. A comparative overlay of FT-IR spectra of poly (2,5-dimethoxyaniline) samples synthesized by varying ratio of binary oxidants $\left(\mathrm{FeCl}_{3}\right.$ :APS).

Table 2. Assignment of various peaks observed in FT-IR spectra of poly(2,5-dimethoxyaniline).

\begin{tabular}{cccccc}
\hline $\begin{array}{c}\text { Absorption } \\
\text { Band }\end{array}$ & PDMA1 & PDMA2 & PDMA3 & PDMA4 & PDMA5 \\
\cline { 2 - 6 } & - & 1739.4 & 1739.4 & 1739.4 & 1739.4 \\
\hline $\begin{array}{c}\text { Aromatic -C=O } \\
\quad \text { Streching } \\
\text { Aromatic Ring } \\
\quad \text { Quinoid }\end{array}$ & 1571.9 & 1513.3 & 1516.6 & 1506.9 & 1503.9 \\
$\begin{array}{c}\text { Aromatic Ring } \\
\text { Benzenoid }\end{array}$ & 1485.0 & 1442.7 & 1424.2 & 1440.1 & 1442.1 \\
$\begin{array}{c}\text { C-N Stretching } \\
\text { C-N }\end{array}$ & 1280.4 & 1273.8 & 1280.5 & 1276.7 & 1298.3 \\
$\begin{array}{c}\text { Stretching } \\
\text { C-H Bending } \\
\text { (in plane) }\end{array}$ & 1203.7 & 1215.3 & 1215.5 & 1215.6 & 1217.2 \\
$\begin{array}{c}\text { C-H bending } \\
\text { (out of plane) }\end{array}$ & 815.7 & 825.1 & 995.7 & 815.8 & 831.2 \\
\hline
\end{tabular}

The key absorption bands that occur in FT-IR spectra of PDMA at $1500-1600 \mathrm{~cm}^{-1}$ and $1400-1500 \mathrm{~cm}^{-1}$ are assigned to the quinoid and benzenoid ring units, respectively [20]. These bands are observed in all the samples synthesized for the present work. The peak at $\sim 1740 \mathrm{~cm}^{-1}$, arising due to aromatic $-\mathrm{C}=\mathrm{O}$ stretching vibration, has been observed in the samples; PDMA2, PDMA3, PDMA4 and PDMA5. However, it could not be observed in PDMA1 i.e., the sample synthesized by $100 \% \mathrm{FeCl}_{3}$. This arrival of the peak can be due to over oxidation of conjugate moiety which in turn influences the carrier mobility. The bands that appear in the range of 1280 $1300 \mathrm{~cm}^{-1}$ correspond to the characteristic C-N stretching [21] vibration and provide evidence of the presence of aromatic amine unit in PDMA. The absorption at 1200 $1220 \mathrm{~cm}^{-1}$ can be attributed to the combined stretching vibration of C-N $\mathrm{N}^{+}$and $\mathrm{C}-\mathrm{C}$. The in-plane and out of-plane bending of $\mathrm{C}-\mathrm{H}$ vibrations are indicated by the presence of absorption peaks at 1027 and $815 \mathrm{~cm}^{-1}$, respectively. These are the characteristic bands of 1,4 substituted aromatic nuclei i.e. bridging of two aromatic benzene ring units through C-N-C bonding at 1,4-position [20,22]. These bands confirm the synthesis of polymer PDMA. There is also a signature of cross linking of 1,2 and 1,3 -substituted aromatic nuclei, which can be observed in the range of $700-600 \mathrm{~cm}^{-1}$. The absorption band due to quinoid ring unit shows a decrease in its intensity relative to benzenoid ring unit while going from PDMA1 to PDMA3. However, from PDMA3 to PDMA4, the absorption band of benzenoid ring unit shows a significant presence together with the quinoid ring unit. This behavior depicts the preference of benzenoid ring unit over quinoid ring unit for the polymer synthesized by binary oxidant $\mathrm{FeCl}_{3}$ and APS in 50:50 (wt\%) ratio (PDMA3), and hence a good oxidation as well as doping are obtained.

\subsection{Uv-Vis Analysis}

Uv-vis spectra of various samples of PDMA are shown in Figure 3. The absorption band at 300 - $330 \mathrm{~nm}$ corresponds to $\pi-\pi^{*}$ transition in the benzenoid ring unit whereas the broad absorption band in the range of 480 $640 \mathrm{~nm}$ has been attributed to the charge transfer exciton of the quinoid ring unit in the PDMA [10,20,23]. This broad absorption band at $480-640 \mathrm{~nm}$ is the conformation of the polymer oxidation and may be considered as a characteristic of the degree of oxidation of the polymer. It can be seen in Figure 3 that the peaks in the range 300 - $330 \mathrm{~nm}$ and 400 - $500 \mathrm{~nm}$ are not sharp but rather broad and diffused. This may be due to the fact that $\mathrm{FeCl}_{3}$ oxidant prefers the presence of benzenoid ring unit as compared to quinoid ring unit. The photophysical characterizations (FT-IR and Uv-vis) of PDMA2 and PDMA4 show almost similar behavior with a slight variation in 


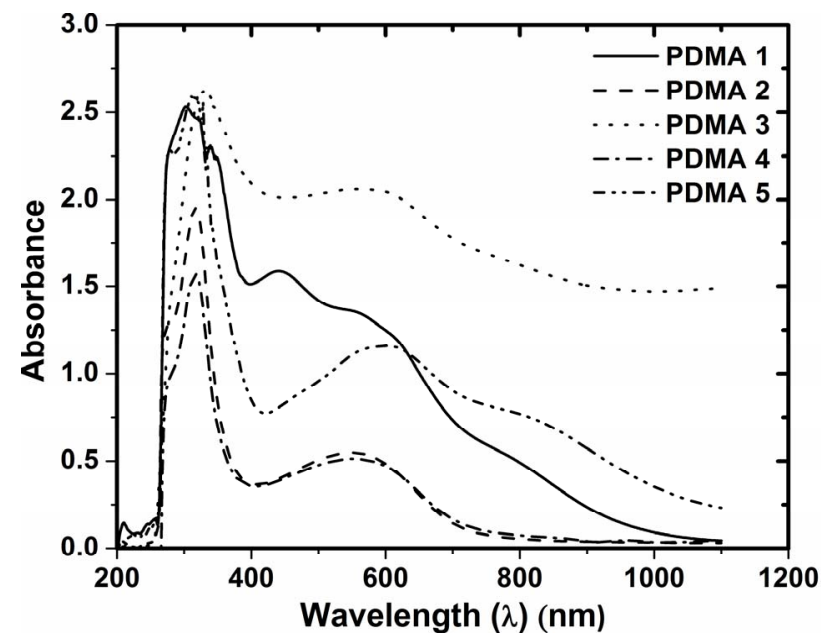

Figure 3. The Uv-vis spectra of various samples of poly (2,5-dimethoxyaniline) synthesized by chemical oxidative polymerization technique by varying ratio of binary oxidants ( $\mathrm{FeCl}_{3}$ : APS).

absorption intensity in Uv-vis spectra in the range 300 $330 \mathrm{~nm}$. Since there is no change in the position of the peak and only the intensity of the peak $(300-330 \mathrm{~nm})$ is higher for PDMA2 as compared to PDMA4, it can be said that the benzenoid units in the polymer architecture dominates over quinoid units. Ginder et al. [24] have observed that the increase in the dihedral angle or the torsion angle between the adjacent aromatic rings of the polymer could cause a hypsochromic shift.

It can be seen in Figure 3 that the peak at $337 \mathrm{~nm}$ in PDMA3 would show a similar hypsochromic shift if it goes on either side of the disproportionate ratio of oxidants for polymerization i.e. either towards PDMA1 or PDMA5. This behavior could be explained by the steric factors which indirectly affect the dihedral angle of the adjacent ring units [24].

\subsection{Thermal Analysis}

The thermal analysis of the PDMA samples has been performed by differential scanning calorimetry (DSC) in the temperature range $25^{\circ} \mathrm{C}-450^{\circ} \mathrm{C}$ at scan rate of $10^{\circ} \mathrm{C} \cdot \mathrm{min}^{-1}$ under nitrogen atmosphere. As a representative result, the thermograms for samples PDMA1, PDMA3 and PDMA5 are shown in Figure 4. There are mainly three regions $\left(25^{\circ} \mathrm{C}-150^{\circ} \mathrm{C}, 150^{\circ} \mathrm{C}-300^{\circ} \mathrm{C}\right.$ and $\left.300^{\circ} \mathrm{C}-450^{\circ} \mathrm{C}\right)$ of energy change observed in PDMA samples which comprise of two endothermic peaks and one exothermic peak, respectively.

The first endothermic peak observed in the range $25^{\circ} \mathrm{C}$ - $150^{\circ} \mathrm{C}$ can be attributed to the release of solvent entrapped in the PDMA samples. This peak has been observed at $\sim 100^{\circ} \mathrm{C}, 110^{\circ} \mathrm{C}$ and $90^{\circ} \mathrm{C}$, for PDMA1, PDMA3 and PDMA5, respectively. The second endothermic peak has been observed in the temperature region $150^{\circ} \mathrm{C}$ -

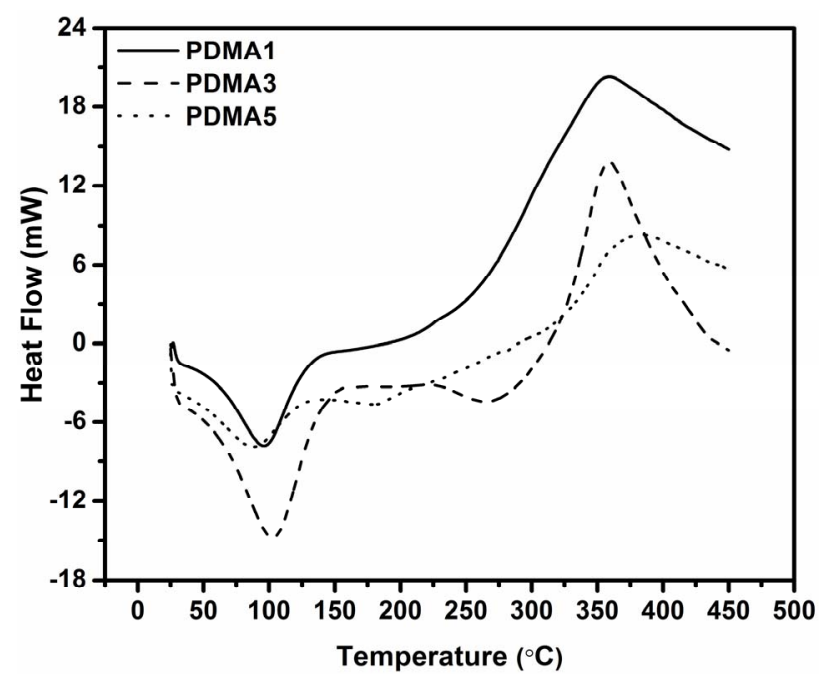

Figure 4. Representative results of differential scanning calorimetric (DSC) spectra of poly(2,5-dimethoxyaniline) samples synthesized by varying ratio of binary oxidants (FeCl ${ }_{3}$ :APS) for samples PDMA1, PDMA3 and PDMA5.

$300^{\circ} \mathrm{C}$ of the thermogram. The change in energy in this region is associated with the morphological changes $[25,26]$ taking place due to melting of the polymer. This indicates that the peaks are centered around glass transition temperature $\left(\mathrm{T}_{\mathrm{g}}\right)$ which is $\sim 207^{\circ} \mathrm{C}, 275^{\circ} \mathrm{C}$, and $180^{\circ} \mathrm{C}$ for samples PDMA1, PDMA3 and PDMA5, respectively. Although for sample PDMA1, the peak around $T_{g}$ is a broad hump but its center is near $\sim 207^{\circ} \mathrm{C}$. The well-defined peak corresponding to melting of PDMA is observed for PDMA3. This peak also shows a shift in $\mathrm{T}_{\mathrm{g}}$ towards higher temperature for PDMA3 and is due to its enhanced crystallinity as compared to PDMA1 and PDMA5. The third exothermic peak, arising in the temperature region $300^{\circ} \mathrm{C}-450^{\circ} \mathrm{C}$, is due to the degradation of the polymer backbone. Thermogram of a crystalline matrix will have a sharp temperature zone for the degradation and will broaden as the amorphousity gets enhanced in the polymer matrix [27]. Thus the well-defined and sharp peak of degradation for PDMA3 again indicates the higher order of crystallinity in this sample as compared to PDMA1 and PDMA5.

\subsection{X-Ray Diffraction Analysis}

The conducting polymers are usually amorphous/semicrystalline in nature but their characteristic X-ray diffraction (XRD) peaks due to $\pi-\pi^{*}$ interaction have been reported in literature [28]. XRD patterns of PDMA1, PDMA2, PDMA3, PDMA4 and PDMA5 are depicted in Figure 5.

XRD data revels that the polymer crystallinity is strongly dependent on the ratio of the two oxidants used for polymer synthesis. PDMA1 synthesized with $\mathrm{FeCl}_{3}$ (as the only oxidant) shows a broad hump and the XRD 


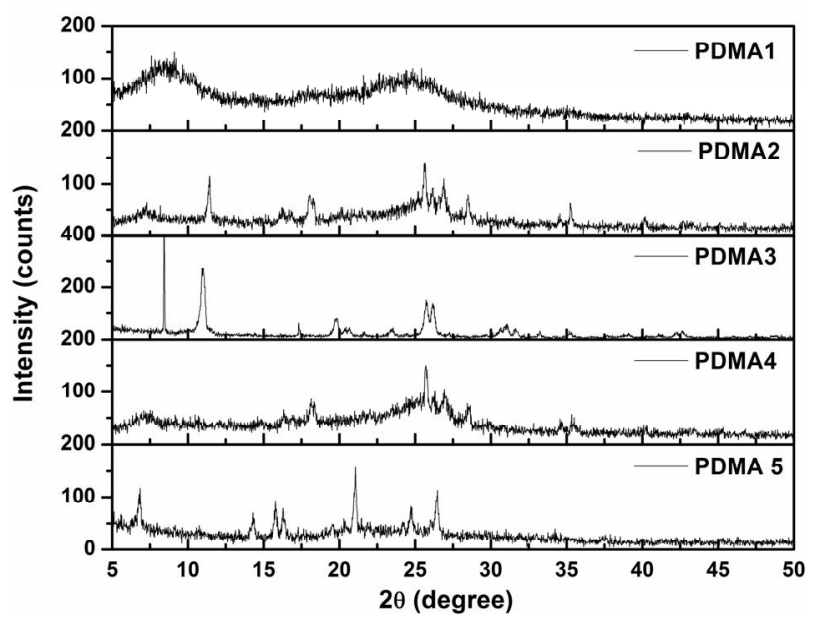

Figure 5. XRD patterns of poly(2,5-dimethoxyaniline) samples synthesized by varying ratio of binary oxidants $\left(\mathrm{FeCl}_{3}\right.$ : APS).

spectrum is amorphous in nature. The addition of APS in the binary oxidants $\left(\mathrm{FeCl}_{3}\right.$ and APS) induces crystallinity as is evident from the appearance of sharp peaks when the APS content increases in PDMA samples (PDMA2 to PDMA5). The intensity counts increase for sample PDMA1 to PDMA3, then there is a reduction in the intensity counts for the PDMA samples, PDMA4 to PDMA5. The XRD study reveals that the polymer with the oxidant ratio $\mathrm{FeCl}_{3}$ :APS (50:50) i.e. PDMA3, has the highest crystallinity which indicates that it has a better structural ordering. Sample PDMA2 and PDMA4 show similar photophysical behavior. However, PDMA2 shows a few crystalline peaks at lower $2 \theta$ value which is not observed in PDMA4 indicating thereby slight better ordering in overall structure of PDMA2. The crystallinity of PDMA is governed by two competing factors. The cross linking between 1,2- and 1,3-disubstituted aromatic nuclei leads to amorphousity whereas the presence of benzenoid ring units results in better laminar stacking and crystallineity which is generally attributed to the ordering of polymer chains as well as the extent of formation of benzenoid or quinoid ring units. The addition of APS in the binary oxidant brings about regular pattern and better ordered form of benzenoid structure leading to better crystallinity. Hence the photo-physical characterization and thermal analysis results elucidated above have been confirmed by X-ray diffraction data.

\subsection{Morphological Analysis}

Although the scanning electron micrographs of all the PDMA samples has been reported in our recent work, [19] the same has been reported here on single magnifycation (Figure 6) for showing its correlation with X-ray diffraction (Figure 5) and dc conductivity (Figure 7) data. In Figures 6(a)-(e) the amorphous and crystalline regions are distinctly visible which are represented by arrows and ellipses, respectively. The larger grains appear to be composed of thin (nearly two dimensional) sheets of polymer stacked together forming micron size grains. As discussed above, the ratio of APS and $\mathrm{FeCl}_{3}$ seems to play an important role in determining the morphology and crystallinity of PDMA. The largest grains are observed in PDMA3 synthesized with the binary oxidant $\mathrm{FeCl}_{3}$ :APS (50:50 wt\%). However, it is interesting to note that the amorphous regions are minimum in PDMA5, which was prepared with only APS. This sample shows the growth of some needle type gains of varying dimensions in addition to micron size grains. PDMA1 shows nearly amorphous character and is devoid of any structural ordering. It is evident from Figure 5 that crystallinity increases as we go from sample PDMA1 to PDMA3. The X-ray diffraction results agree well with the surface morphologyical behavior of PDMA in the present investigation.

\subsection{Room Temperature dc Conductivity $\left(\sigma_{\mathrm{dc}}\right)$}

The variation of $\sigma_{\mathrm{dc}}$ data of different PDMA samples as a function of oxidant ratio ( $\mathrm{FeCl}_{3}$ :APS) is shown in Figure 7 at room temperature $(\sim 300 \mathrm{~K})$. It is evident from Figure 7 that as the APS content increases, the $\sigma_{\mathrm{dc}}$ increases upto a ratio of $50: 50\left(\mathrm{FeCl}_{3}\right.$ :APS) content and after that it decreases. It has been reported in literature $[29,30]$ that the magnitude of dc conductivity increases with increase in number of benzenoid ring units in PDMA back-bone. However, with the introduction of APS in the binary oxidants, the enhanced cross-linking and interconnectivity between the grains also contribute to the variation in the room temperature dc conductivity $\left(\sigma_{\mathrm{dc}}\right)$. The dependence of dc conductivity on the ratio of oxidant indicates that the extent of benzenoid structure and cross-linking due to incorporation of APS are optimized in case of sample PDMA3 resulting in maximum value of $\sigma_{\mathrm{dc}}$ for this sample. Further increase of APS in binary oxidant (PDMA4 and PDMA5) results into increased cross linkages of the polymer thus decreasing the dc conductivity (Table 1). The observed dc conductivity data (Figure 7) is in accordance with the structural, thermal and photophysical investigations presented above. The above discussion supports that the structural and electrical properties are influenced by the extent of presence of $\mathrm{FeCl}_{3}$ and/or APS in the binary oxidant used for the synthesis of conducting polymer PDMA for the present investigation.

\subsection{Ammonia Sensing}

Chemical sensors transform the concentrations of analytes to detectable physical signals such as currents, absorbance, mass or acoustic variables. When a sensor is 

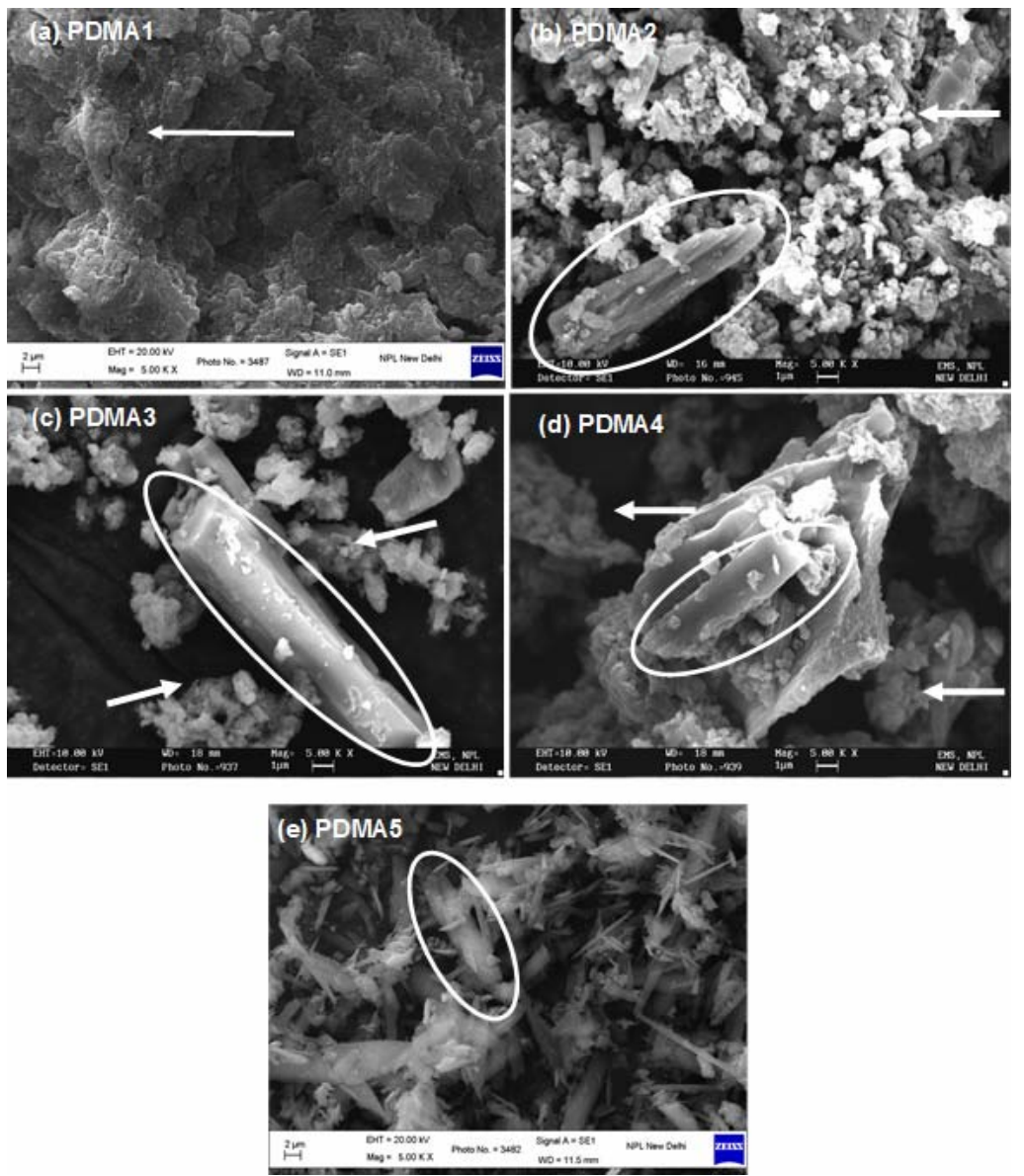

Figure 6. SEM images of poly(2,5-dimethoxyaniline) samples synthesized by varying ratio of binary oxidants (FeCl ${ }_{3}$ :APS). (a) PDMA1; (b) PDMA2; (c) PDMA3; (d) PDMA4; and (e) PDMA5.

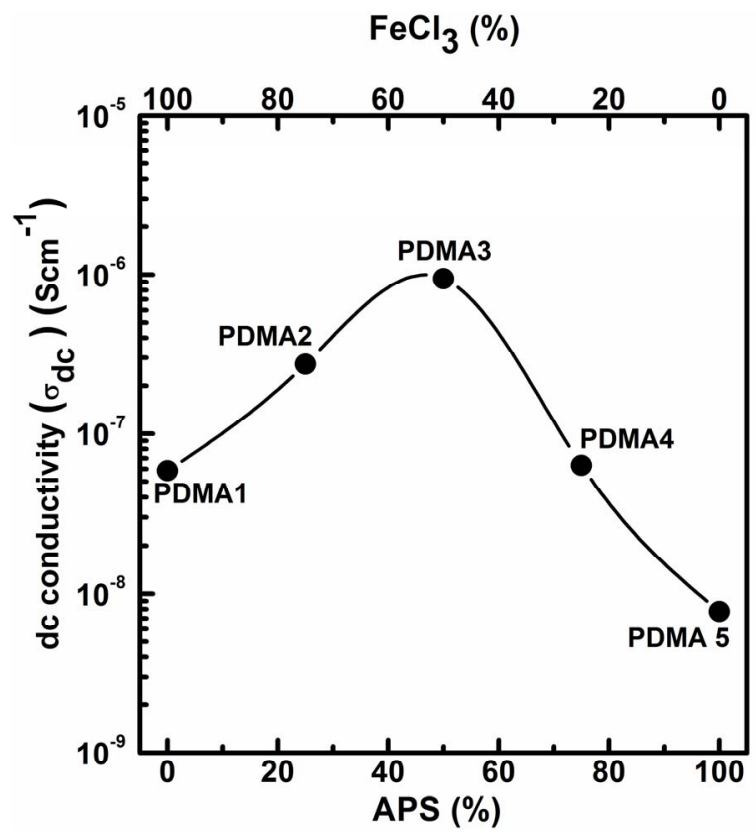

Figure 7. Plot of room temperature $(\sim 300 \mathrm{~K})$ dc conductiveity $\left(\sigma_{\mathrm{dc}}\right)$ of different samples of poly(2,5-dimethoxyaniline) as a function of varying binary oxidants $\left(\mathrm{FeCl}_{3}\right.$ :APS). exposed to the vapor of an analyte, the active sensing material of the sensor interacts with the analyte, causing changes in physical properties of the sensing material. PDMA is a substituted form of PANI and its doped state can be controlled by acid/base reactions. This is widely used to detect acidic and basic gases. Figure 8 shows the variation of surface current of sample PDMA3 with exposure to different volume of ammonia gas. When PDMA is exposed to ammonia gas, it undergoes dedoping by deprotonation leading to decrease in the surface current. This is due to the fact that the protons on -NH- group get transferred on to $\mathrm{NH}_{3}$ molecules to form ammonium ions whereas PDMA itself turns into its conjugated-base form. This process is reversible, and in fact, when ammonia atmosphere is removed, the ammonium ions can be decomposed into ammonia gas and proton. After reaction with acidic gases, such as $\mathrm{HCl}, \mathrm{H}_{2} \mathrm{~S}$ and $\mathrm{CO}_{2}$ (in presence of water), PDMA gets protonated [31-34]. It has been reported [31] earlier that $\mathrm{H}_{2}$ can be adsorbed on to the positive charged nitrogen atoms of PDMA, and then gets dissociated into hydrogen atoms. The formation of new $\mathrm{N}-\mathrm{H}$ bonds between the hydrogen and nitrogen has reduced the surface current of PDMA [35]. 


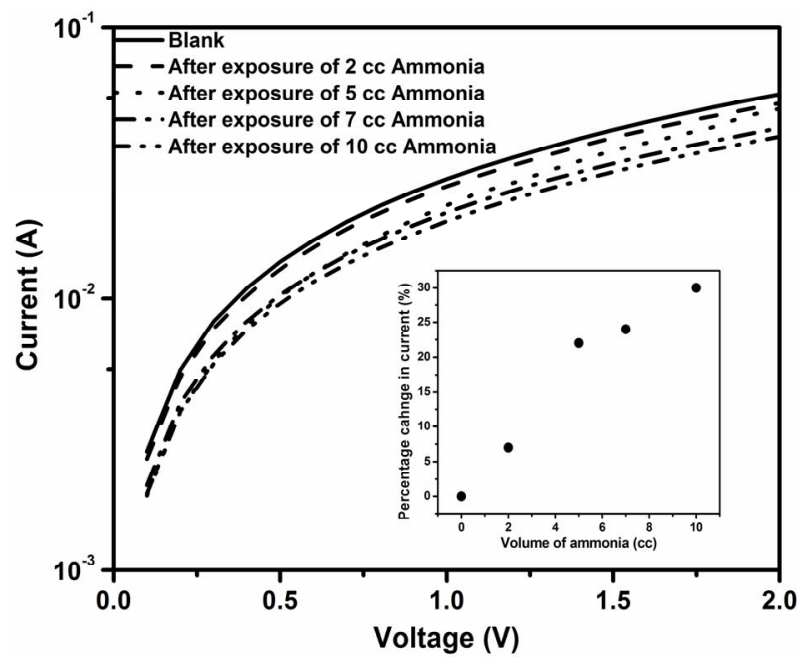

Figure 8. Plot showing variation in surface current of poly (2,5-dimethoxyaniline) (PDMA3) spin casted film before and after exposure to ammonia gas. Inset show the \% change in surface current as a function of volume of exposed ammonia gas.

The inset of Figure 8 exhibits the proportional dependence of the percentage change in surface current with respect to different amount of exposed ammonia gas.

\section{Conclusion}

The photo-physical investigations indicate the presence of combination of benzenoid and quinoid structure in PDMA. APS in the binary mixture of oxidant controls the ordering in the polymer leading to crystalline peaks in XRD data. SEM shows the presence of amorphous and crystalline domains. By altering the ratio of $\mathrm{FeCl}_{3}$ to APS in the reaction mixture, better photo-physical and structurally ordered polymer PDMA3 has been synthesized. DSC confirms the better crystallinity for sample PDMA3. From the present investigations it has been concluded that the PDMA3 synthesized by binary oxidant ratio of ( $\mathrm{FeCl}_{3}$ :APS) (50:50 wt\%) gives better photo-physical and structurally ordered polymer. PDMA3 not only exhibits maximum conductivity (Table 1) but also shows surface electrical behavior susceptible to absorbed ammonia gas. The percentage change in surface current shows a proportional increase with increase in volume of exposed ammonia gas.

\section{Acknowledgements}

The authors are grateful to Director, National Physical Laboratory, New Delhi for his permission to publish this work. The authors are thankful to Drs. H. K. Singh, R. P. Pant and S. K. Dhawan of National Physical Laboratory, New Delhi for cooperation. Three of us (AK, KA and RS) are thankful to Council of Scientific \& Industrial Research (CSIR), Government of India, New Delhi for the award of Junior Research Fellowship and Emeritus Scientist Fellowship, respectively.

\section{REFERENCES}

[1] J. Y. Kim, K. Lee, N. E. Coates, D. Moses, T-Q. Nguyen, M. Dante and A. J. Heeger, "Efficient Tandem Polymer Solar Cells Fabricated by All-Solution Processing," Science, Vol. 317, No. 5835, 2007, pp. 222-225. doi:10.1126/science. 1141711

[2] I. Kymissis, "Organic Field Effect Transistors: Theory, Fabrication and Characterization," Springer Science, New York, 2009.

[3] H. K. Song and G. R. Palmore, "Redox-Active Polypyrrole: Toward Polymer-Based Batteries," Advance Materials, Vol. 18, No. 13, 2006, pp. 1764-1768. doi:10.1002/adma.200600375

[4] A. A. Athawale, S. V. Bhagwat and P. P. Katre, "Nanocomposite of Pd-Polyaniline as a Selective Methanol Sensor," Sensors Actuators B: Chemical, Vol. 114, No. 1, 2006, pp. 263-267. doi:10.1016/j.snb.2005.05.009

[5] T.-K. Chang, C.-C. Chang and T.-C. Wen, "The Methanol Adsorption Behavior on Platinum/Poly(2,5-Dimethoxyaniline) Composites for Application In Methanol Sensing," Journal of Power Sources, Vol. 185, No. 2, 2008, pp. 603608. doi:10.1016/i.jpowsour.2008.09.033

[6] M. Arulepp and L. Permann, "Influence of the Solvent Properties on the Characteristics of a Double Layer Capacitor," Journal of Power Sources, Vol. 133, No. 2, 2004, pp. 320-328. doi:10.1016/i.jpowsour.2004.03.026

[7] W. Lu, A. G. Fadeev, B. Qi and B. R. Mattes, "Fabricating Conducting Polymer Electrochromic Devices Using Ionic Liquids," Journal of The Electrochemical Society, Vol. 151, No. 2, 2004, pp. H33-H39. doi:10.1149/1.1640635

[8] Q. Sun, M. Park and Y. Deng, "Dendritic Superstructure Formation of Polyaniline Prepared Using a Water-Soluble Polyelectrolyte Copolymer as the Support Matrix," Material Letters, Vol. 61, No. 14, 2007, pp. 3052-3055. doi:10.1016/j.matlet.2006.10.073

[9] J. H. Hwang and S. C. Yang, "Morphological Modification of Polyaniline Using Polyelectrolyte Template Molecules," Synthetic Metals, Vol. 29, No. 1, 1989, pp. 271276. doi:10.1016/0379-6779(89)90306-8

[10] S. E. Mavundla, G. F. Malgas, P. Baker and E. I. Iwuoha, "Synthesis and Characterization of Novel Nanophase Hexagonal Poly(2,5-dimethoxyaniline)," Electroanalysis, Vol. 20, No. 21, 2008, pp. 2347-2353. doi:10.1002/elan.200804326

[11] D. W. Hatchett and M. Josowicz, "Composites of Intrinsically Conducting Polymers as Sensing Nanomaterials," Chemical Reviews, Vol. 108, No. 2, 2008, pp. 746-769. doi: $10.1021 / \mathrm{cr} 068112 \mathrm{~h}$

[12] P. Li, T. C. Tan and J. Y. Lee, "Corrosion Protection of Mild Steel by Electroactive Polyaniline Coatings," Synthetic Metals, Vol. 88, No. 3, 1997, pp. 237-242. doi:10.1016/S0379-6779(97)03860-5

[13] J. Huang and R. B. Kaner, "A General Chemical Route to 
Polyaniline Nanofibers," Journal of the American Chemical Society, Vol. 126, No. 3, 2004, pp. 851-855. doi:10.1021/ja0371754

[14] V. Bavastrello, E. Stura, S. Carrara, V. Erokhin and C. Nicolini, "Poly(2,5-Dimethylaniline)-MWNTS Nanocomposite: A New Material for Conductometric Acid Vapours Sensor," Sensors and Actuators B: Chemical, Vol. 98, No. 2, 2004, pp. 247-253. doi:10.1016/j.snb.2003.10.020

[15] P. Yin and P. A. Kilmartin, "Formation of Poly-2,5-Dimethoxyaniline on Steels," Current Applied Physics, Vol. 4, No. 2, 2004, pp. 141-143. doi:10.1016/j.cap.2003.10.016

[16] B. Palys, A. Kudelski, A. Stankiewicz and K. Jackowska, "Influence of Anions on Formation and Electroacitivity of Poly-2,5-Dimethoxyaniline," Synthetic Metals, Vol. 108, No. 2, 2000, pp. 111-119. doi:10.1016/S0379-6779(99)00180-0

[17] L. Yu, J. I. Lee, K. W. Shin, C. E. Park and R. Holze, "Preparation of Aqueous Polyaniline Dispersions by Micellar-Aided Polymerization," Journal of Applied Polymer Science, Vol. 88, No. 6, 2003, pp. 1550-1555. doi:10.1002/app.12127

[18] Z. Zhang, Z. Wei and M. Wan, "Nanostructures of Polyaniline Doped with Inorganic Acids," Macromolecules, Vol. 35, No. 15, 2002, pp. 5937-5942. doi:10.1021/ma020199v

[19] R. K. Singh, A. Kumar and R. Singh, "Mechanism of Charge Transport in Poly(2,5-Dimethoxyaniline)" Journal of Applied Physics, Vol. 107, No. 11, 2010, p. 113711. doi:10.1063/1.3443564

[20] D. C. Trivedi, "Handbook of Organic Conductive Molecules and Polymers," Wiley, New York, 1997, pp. 505-572.

[21] H. K. Chaudhari and D. S. Kelkar, "Investigation of Structure and Electrical Conductivity in Doped Polyaniline," Polymer International, Vol. 42, No. 4, 1997, pp. 380-384. doi:10.1002/(SICI)1097-0126(199704)42:4<380::AID-PI 727>3.0.CO;2-F

[22] J. L. Camalet, J. C. Lacroix, S. Aeiyach and P. C. Lacaze, "Characterization of Polyaniline Films Electrodeposited on Mild Steel in Aqueous $p$-Toluenesulfonic Acid Solution," Journal of Electroanalytical Chemistry, Vol. 445, No. 1, 1998, pp. 117-124. doi:10.1016/S0022-0728(97)00526-3

[23] N. Kohut-Svelko, S. Reynaud and J. Francois, "Synthesis and Characterization of Polyaniline Prepared in the Presence of Nonionic Surfactants in an Aqueous Dispersion," Synthetic Metals, Vol. 150, No. 2, 2005, pp. 107-114. doi:10.1016/i.synthmet.2004.12.022

[24] J. M. Ginder and A. J. Epstein, "Role of Ring Torsion Angle in Polyaniline: Electronic Structure and Defect States," Physics Review B, Vol. 41, No. 15, 1990, pp. 10674-10685. doi:10.1103/PhysRevB.41.10674

[25] G. M. Neelgund, E. Hrehorova, M. Joyce and V. Blizn- yuk, "Synthesis and Characterization of Polyaniline Derivative and Silver Nanoparticle Composites," Polymer International, Vol. 57, No. 10, 2008, pp. 1083-1089. doi:10.1002/pi.2445

[26] B. C. Roy, M. D. Gupta, L. Bhowmik and J. K. Ray, "Synthesis and Characterization of Poly(2,5-Dimethoxyaniline) and Poly(Aniline-co-2,5-dimethoxyaniline): The Processable Conducting Polymers," Bulletin of Materials Science, Vol. 24, No. 4, 2001, pp. 389-396. doi:10.1007/BF02708636

[27] R. Singh, J. Kumar, R. K. Singh, A. Kaur, R. D. P. Sinha and N. P. Gupta, "Low Frequency ac Conduction and Dielectric Relaxation Behavior of Solution Grown and Uniaxially Stretched Poly(Vinylidene Fluoride) Films," $\mathrm{Po}$ lymer, Vol. 47, No. 16, 2006, pp. 5919-5928. doi:10.1016/j.polymer.2006.06.023

[28] B. Dong, B.-L. He, C.-L. Xu and H.-L. Li, "Preparation and Electrochemical Characterization of Polyaniline/MultiWalled Carbon Nanotubes Composites for Supercapacitor," Material Science and Engineering B, Vol. 143, No. 1, 2007, pp. 7-13. doi:10.1016/j.mseb.2007.06.017

[29] P. F. Van Hutten and G. Hadzioannou, "Handbook of Organic Conductive Molecules and Polymers," Wiley, New York, 1997, pp. 1-86.

[30] R. Singh, V. Arora, R. P. Tandon and S. Chandra, "Transport and Structural Properties of Polyaniline Doped With Monovalent and Multivalent Ions," Polymer, Vol. 38, No. 19, 1997, pp. 4897-4902. doi:10.1016/S0032-3861(97)00013-X

[31] S. Virji, J. X. Huang, R. B. Kaner and B. H Weiller, "Polyaniline Nanofiber Gas Sensors: Examination of Response Mechanisms," Nano Letters, Vol. 4, No. 3, 2004, pp. 491 496. doi:10.1021/n1035122e

[32] Q. Hao, X. Wang, L. Lu, X. Yang and V. M. Mirsky, "Electropolymerized Multilayer Conducting Polymers with Response to Gaseous Hydrogen Chloride," Macromolecular Rapid Communications, Vol. 26, No. 13, 2005, pp. 1099-1103. doi:10.1002/marc.200500114

[33] S. Virji, J. D. Fowler, C. O. Baker, J. X. Huang, R. B. Kaner and B. H. Weiller, "Polyaniline Nanofiber Composites with Metal Salts: Chemical Sensors for Hydrogen Sulfide," Small, Vol. 1, No. 6, 2005, pp. 624-627. doi:10.1002/smll.200400155

[34] K. Ogura, H. Shiigi, T. Oho and T. Tonosaki, " $\mathrm{A} \mathrm{CO}_{2}$ Sensor with Polymer Composites Operating at Ordinary Temperature," Journal of the Electrochemical Society, Vol. 147, No. 11, 2000, pp. 4351-4355. doi:10.1149/1.1394068

[35] S. Virji, R. B. Kaner and B. H. Weiller, "Hydrogen Sensors Based on Conductivity Changes in Polyaniline Nanofibers," Journal of Physical Chemistry B, Vol. 110, No. 44, 2006, pp. 22266-22270. doi:10.1021/jp063166g 